\title{
Investigation of surface modification of casein films by rennin enzyme action using micro-beam grazing incidence small angle $X$-ray scattering
}

\author{
Ronald Gebhardt ${ }^{1,2 *}$, Manfred Burghammer ${ }^{1}$, Christian Riekel ${ }^{1}$, \\ Ulrich KulozIK $^{2,3}$, Peter Müller-BuschBaum ${ }^{4}$ \\ ${ }^{1}$ European Synchrotron Radiation Facility, BP 220, 38043 Grenoble Cedex, France \\ ${ }^{2}$ Chair for Food Process Engineering and Dairy Technology, Technische Universität München, \\ Weihenstephaner Berg 1, 85354 Freising-Weihenstephan, Germany \\ ${ }^{3}$ ZIEL Center of Nutrition and Food Research, Technology Section, Technische Universität München, \\ Weihenstephaner Berg 1, 85354 Freising-Weihenstephan, Germany \\ ${ }^{4}$ Physik-Department, TU München, LS E13, James-Franck-Str. 1, 85747 Garching, Germany
}

Received 11 May 2009 - Revised 16 September 2009 - Accepted 15 October 2009

Published online 17 December 2009

\begin{abstract}
Micro-beam grazing incidence small angle X-ray scattering ( $\mu$ GISAXS) scans were performed to investigate structural changes that occur after deposition of a droplet of rennin on a casein film. The subsequent diffusion of the droplet into the film led to a lateral and vertical concentration gradient of rennin. As a result of the enzyme action, the film surface became roughened and the formation of islands - evident. The altered surface morphology led to a variation in the $\mu$ GISAXS pattern, more precisely to the occurrence of a second so-called Yoneda peak. As for the untreated casein film, the mean size of the micelle components (casein micelles, substructure and colloidal calcium phosphate) remained constant within the rennin droplet area. In contrast, a broadening of their corresponding size distributions could be detected. Finally, we discuss the potential of GISAXS scanning experiments with micrometer-sized X-ray beams in view of problems with the interpretation of the data obtained from imaging techniques such as atomic force microscopy.
\end{abstract}

casein micelle / rennin enzyme / casein film / $\mu$ GISAXS / synchrotron radiation

摘要 - 微束掠入射小角 $\mathbf{X}$-射线散射法探测凝乳酶表面改性后的酪蛋白膜。利用微束掠入 射小角 X-射线散射法 ( $\mu$ GISAXS) 研究了凝乳酶液覆盖酪蛋白膜表面的结构变化。凝乳酶的 扩散使其在横向和纵向均形成浓度梯度。由于酶的作用, 薄膜表面变粗粘, 并形成岛屿形状, 从 而改变了表面形态, 导致 $\mu$ GISAXS 模式发生变化, 出现了所谓的第二 Yoneda 峰。与未经 处理的酪蛋白膜一样, 在凝乳酶液分布范围内, 胶束组分 (包括酪蛋白胶束、亚胶束和胶体磷酸 钲) 的平均粒径保持恒定, 但是, 能检测到的粒径分布范围扩大。最后我们用毫米级 X-射线 GISAXS 扫描实验解释了原子力显微镜 (AFM) 成像技术获得的数据所存在的问题。

\section{酪蛋白胶束 / 凝乳酶 / 酪蛋白膜 / $\mu$ GISAXS / 同步辐射}

Résumé - Modification de la surface de films de caséine par l'action enzymatique de la chymosine mise en évidence par diffusion aux petits angles en incidence rasante de rayons $X$ de taille micrométrique ( $\mu$ GISAXS). Des mesures de diffusion aux petits angles

*Corresponding author (通讯作者): ronald.gebhardt@esrf.fr 
en incidence rasante de rayons $\mathrm{X}$ de taille micrométrique ( $\mu$ GISAXS) ont été réalisées à travers une gouttelette de chymosine déposée sur un film de caséine, afin d'en étudier les changements de structure. Du fait de l'action de l'enzyme, la surface du film devenait rugueuse et la formation d'îlots apparaissait. Ce changement de morphologie de surface conduisait à une variation des données $\mu$ GISAXS, faisant en particulier apparaître le second pic « Yoneda ». Comme dans le film de caséine non traité, les tailles moyennes des composants micellaires (micelle de caséines, sous-structure et phosphate de calcium colloïdal) demeuraient constantes à l'intérieur de l'aire de la gouttelette de chymosine, mais un élargissement de leur distribution de tailles était mis en évidence. Enfin, le potentiel de la technique GISAXS avec des rayons $X$ de taille micrométrique est discuté au regard des problèmes d'interprétation des données obtenues par les techniques d'imagerie comme la microscopie à force atomique (AFM).

micelle de caséine / chymosine / film de caséine / $\mu$ GISAXS / radiation synchrotron

\section{INTRODUCTION}

The actual structure of casein micelles is still a scientific challenge. Additionally, the direct impact of enzyme action on the casein structure is difficult to detect. These difficulties of the structure determination are a result of the randomly folded casein monomers that built up the micelle and the variety of bound non-protein components. Both characteristics lead to the heterogeneous nature of casein micelles, which is reflected among others in their large size distribution. More precisely, casein micelles are mainly built up by three different caseins $\left(\alpha_{\mathrm{s} 1^{-}} \alpha_{\mathrm{s} 2^{-}}, \beta\right.$ - and $\kappa$-casein) and colloidal calcium phosphate (CCP). The diameter of the casein micelles ranges from 50 to $500 \mathrm{~nm}$, the mean diameter being $120 \mathrm{~nm}[4]$.

Closely related to the heterogeneous nature is the lack of a crystal structure, so low-resolution methods like small angle scattering (SAS) $[9,11,16,21]$, atomic force microscopy (AFM) [6, 22] and electron microscopy (EM) [3] are applied in order to elucidate structural details. SAS data, obtained by scattering of X-rays or neutrons on a casein micelle suspension, reveal a multi-level structure, which is interpreted differently. Besides the accepted spherical shape of the entire casein micelle, the found substructure at values of the scattering vector of $0.1 \mathrm{~nm}^{-1}$ is assigned to either casein submicelles, an additional smaller casein micelle population - called "casein mini-micelles" the mean distance of CCP particles, or the outer $\kappa$-casein layer. The different interpretations are established in different casein micelle models, namely the casein submicelle model [28], the internal structure model $[12,13]$ and the coat core model $[27,30]$.

In contrast to SAS experiments relying on bulk solutions, the casein sample is investigated in a dried state and immobilized on a solid support with AFM and EM techniques.

Grazing incidence small angle X-ray scattering (GISAXS) represents a link to the imaging techniques, since scattering information is obtained from a sample prepared on a solid support $[5,17,18]$. A detailed comparison of the mentioned surface-sensitive methods can be found elsewhere [7]. Scattering techniques with micrometer-sized X-ray beams can be combined with high-resolution scans of the sample relative to the X-ray beam. Scans across concentration gradients allow studying structure formation processes $[24,26]$, e.g. structural changes of casein micelles have been investigated in a calcium gradient film by $\mu$ GISAXS [5]. The $\mu$ GISAXS technique can also be used to investigate the concentration profiles of substances that are subsequently added to 
casein films. The diffusion of particles through entangled gels is relevant to food safety, drug delivery and processes involving enzymes [1].

In this paper, we report on a study of a casein film dried onto a surface, which was then consciously changed by rennin treatment. More precisely, a $\mu$ GISAXS scan was performed across a concentration profile of rennin that was added to a previously spin-coated casein film. The general aim of our research is to provide a better understanding toward the development of new functional materials on the basis of natural products such as casein micelles.

\section{MATERIALS AND METHODS}

\subsection{Sample preparation}

Commercial-grade skim milk was used to extract casein micelles after removing the low molecular weight proteins by a combined uniform transmembrane pressure micro-filtration and ultrafiltration. After this procedure, the micelles were concentrated and dried in a pilot spray dryer (Niro Atomizer, Copenhagen, Denmark). Details regarding the complete procedure are described in detail in [15].

Casein suspension $(3 \% \mathrm{w} / \mathrm{w})$ was prepared by dissolving the extracted casein micelles in filtered dialyzed water and stirring thoroughly for $5 \mathrm{~h}$ at $20^{\circ} \mathrm{C}$. For the casein film preparation, pre-cleaned glass slides $\left(26 \times 76 \times 0.15 \mathrm{~mm}^{3}\right.$, Menzel Gläser, Braunschweig, Germany) were used as a solid support. The corresponding cleaning protocol of the glass slides can be found elsewhere [17]. The casein suspension was deposited on the glass slide with spin coating using a frequency of $2000 \mathrm{rpm}$ for $30 \mathrm{~s}$.

In order to modify the casein film surface morphology, rennin (Labferment, Carl Roth $\mathrm{GmbH}+\mathrm{Co}$, Karlsruhe, Germany) was used with a declared activity of $900 \mathrm{IMCU} \cdot \mathrm{g}^{-1}$. A rennin enzyme solution $\left(1 \mathrm{mg} \cdot \mathrm{mL}^{-1}\right)$ was prepared by dissolving the Labferment in filtered, distilled water. A droplet of $3 \mu \mathrm{L}$ of the rennin solution was deposited on the film surface using a micropipette. The diffusion of the solution into the casein film led to a vertical and horizontal rennin gradient within the casein film.

\section{2. $\mu$ GISAXS}

The $\mu$ GISAXS experiments were conducted at the ID13 microfocus beamline of the ESRF (European Synchrotron Radiation Facility) in Grenoble, France [23]. $\mu$ GISAXS scattering setup and geometry are depicted in Figure 1. The incoming monochromatic X-ray beam $(\lambda=0.0961 \mathrm{~nm})$ was focused by a Kirkpatrick-Baez (KB) mirror system to a beam size of $1 \times 1 \mu \mathrm{m}$ at the sample position. In the GISAXS geometry, due to geometrical reasons, the beam size was extended in the beam direction by the socalled footprint effect. In order to enable a movement in all rotational and translational degrees of freedom, the sample was mounted on a goniometer head supported on an $x / y / z$ translation unit (not shown in Fig. 1) [23]. Prior to the $\mu$ GISAXS experiment, a vertically positioned microscope was adjusted to the focal spot of the X-ray beam. Furthermore, diffraction on an Ag-behenate standard was used to determine the sample-detector distance $\left(L_{\mathrm{SD}}=802 \mathrm{~mm}\right)$. During the $\mu$ GISAXS experiment, the microscope was used to select an area of the casein film at which the scattering was conducted. Afterwards, the sample was tilted by means of the goniometer to set up a fixed angle of incidence of $\alpha_{\mathrm{i}}=0.55^{\circ}$. The scattered intensity was recorded by a MAR165CCD detector $(2048 \times 2048$ pixels, pixel size $78.94 \mu \mathrm{m})$. To avoid damage of the detector, direct and specular (mirror-like) reflected beam were both blocked with a beamstop. The $\mu$ GISAXS scan was started $1200 \mathrm{~s}$ after the deposition of the rennin droplet. The exposure time per $\mu$ GISAXS pattern was $2 \mathrm{~s}$. 


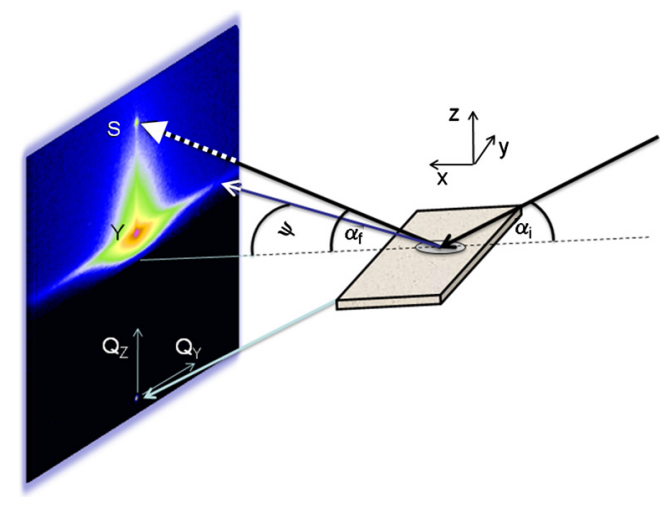

Figure 1. GISAXS scattering geometry with the incident angle $\alpha_{\mathrm{i}}$, the exit angle $\alpha_{\mathrm{f}}$, and the outof-plane angle $\psi$. The specular peak (S) and the Yoneda peak (Y) are indicated as typical features of the GISAXS pattern.

\subsection{Theoretical background}

\subsubsection{GISAXS}

The scattered intensity was recorded in the (yz)-plane as a function of the exit angle $\alpha_{\mathrm{f}}$ and the out-of-plane angle $\psi$. In general, the scattering process leads to a changed directional distribution of the wave vectors $k$ of the used X-rays. Since scattering is an irreversible process, the measuring signal has to be analyzed in the reciprocal space (wave vector space). The components $Q_{y}$ and $Q_{z}$ of the scattering vector $Q$ define the reciprocal space coordinate system calculated from the angles and the wavelength of the X-rays. The GISAXS signal contains specularly and diffusely scattered contributions. The specular peak (S) and the Yoneda Peak (Y) are characteristic features of a GISAXS pattern. The specular peak is obtained at $\alpha_{\mathrm{f}}=\alpha_{\mathrm{i}}$ and corresponds to the mirrored incident beam with respect to its position. The Yoneda peak [31] at $\alpha_{\mathrm{f}}=\alpha_{\mathrm{c}}$ results from the interference of the incident and scattered wave fields. $\alpha_{\mathrm{c}}$ corresponds to the critical angle of the investigated material (casein) and is calculated from its index of refraction. The critical angle of the material is calculated by:

$$
\alpha_{\mathrm{c}}=\sqrt{2 \delta},
$$

where $\delta$ is the real part of the index of refraction which is sufficient for calculation as long as absorption of X-rays by the probed material can be excluded. The value of $\delta$ depends on the chemical constituents, the density of the material and the photon energy, and was calculated using online calculators [10].

Besides simulation of the whole GISAXS pattern, structural information can be obtained from vertical and horizontal cuts (with respect to the sample surface) of the two-dimensional intensity distribution. The so-called detector scan (vertical cut) provides structural information vertical to the sample surface and consequently insights into the structure along the surface normal to the film. An out-of-plane scan (horizontal cut) provides lateral structural information in the $x y$-plane. In order to produce detector and out-of-plane scans, FIT2d software package was used [8].

\subsubsection{Macromolecular diffusion}

Fick's second law was used to describe the spatial and temporal change of the 
rennin concentration $c$ :

$$
(\mathrm{d} c / \mathrm{d} t)_{x}=D \times\left(\partial^{2} c / \partial x^{2}\right)_{t} .
$$

The diffusion constant $D$ has dimensions of $\mathrm{m}^{2} \cdot \mathrm{s}$, the diffusion distance $x$ equals $d-d_{0}$, with $d$, the $\mu$ GISAXS scanning position. Assuming the boundary conditions $c(x, t=0)=c_{0}$ if $x<0$ and $c(x, t=0)=0$ if $x>0$, the solution of equation (2) is

$$
\begin{aligned}
c(x, t)= & c_{0} / 2 \\
& \times\lfloor 1-\operatorname{erf}(x / 2 \times \sqrt{D \times t})\rfloor .
\end{aligned}
$$

The second term of equation (3) is the complementary error function $[1,2]$.

\section{RESULTS AND DISCUSSION}

Figure $2 \mathrm{a}$ shows an atomic force micrograph of a casein film surface. A height profile obtained from a linear cut (black line in Fig. 2a) is shown in Figure 2b. Closely packed casein micelles with mean sizes of $120 \mathrm{~nm}$ are clearly imaged. On closer inspection, a fine structure of the casein micelles could be present. However, the image is not detailed enough to make a clear statement, whether there is a substructure of casein micelles or not. But it should be noted that distinct regions of smaller casein micelle components (so-called mini-micelles) have been imaged on a casein film preparation by AFM [18]. Such mini-micelles could also subsequently attach on the micelle structure during the drying process and mimic a certain substructure of the casein micelle.

Figure 3 gives an overview of the principles of the present $\mu$ GISAXS experiments. The optical micrograph in Figure 3a depicts the top view of a dried rennin droplet deposited on a casein film. A $\mu$ GISAXS scan was performed from the inside of the droplet to the outside across the boundary region. Over a distance of $500 \mu \mathrm{m}$ in steps of
$5 \mu \mathrm{m}$, a total of 100 GISAXS patterns were measured. The series of GISAXS patterns is displayed in Figure 3b. GISAXS patterns measured inside the droplet area are clearly different from those recorded on the untreated casein film. Two patterns in enlarged view are shown for exemplification of this difference (Figs. $3 \mathrm{c}$ and $3 \mathrm{~d}$ ). The difference consists in the occurrence of additional intensity in the GISAXS pattern measured inside the droplet area (Fig. 3c). More precisely, a second Yoneda peak occurs because of the rennin-induced formation of islands on the film surface. Since the island layer has a reduced density compared to the subjacent untreated casein film, we expect a second Yoneda peak at the observed smaller exit angle $\alpha_{\mathrm{f}}$ [20].

Vertical cuts (intensity versus exit angle $\alpha_{\mathrm{f}}$ ) are plotted as a function of scanning distance $d$ in order to analyze the evolution of the two Yoneda peaks (see Fig. 4). After a scanning distance of $400 \mu \mathrm{m}$, the second Yoneda peak at $\alpha_{\mathrm{f}}=$ $0.052^{\circ}$ disappears. This position roughly corresponds to the boundary of the rennin droplet. For all positions outside the rennin droplet, only one single Yoneda peak is observed. Thus, with $\mu$ GISAXS we detect a structural transition of the casein film morphology from a surface covered with islands in the area of the rennin droplet to a more homogeneous surface in the part of the spin-coated casein film which was not treated with the enzyme. Furthermore, plotting of the intensity recorded in the Yoneda peak maxima as a function of the scanning distance reveals a strong dependence between the two peaks and a compensatory effect (see Fig. 5). More precisely, the intensity value of the Yoneda peak at $\alpha_{\mathrm{f}}=0.12^{\circ}$ increases by 1000 counts at the expense of the Yoneda peak at $\alpha_{\mathrm{f}}=0.052^{\circ}$ during the $\mu$ GISAXS scan. Thus, the Yoneda peak intensity at $\alpha_{\mathrm{f}}=0.052^{\circ}$ reflects the rennin concentration gradient which is installed in the vertical and lateral directions due to the diffusion process. Assuming a box-shaped 

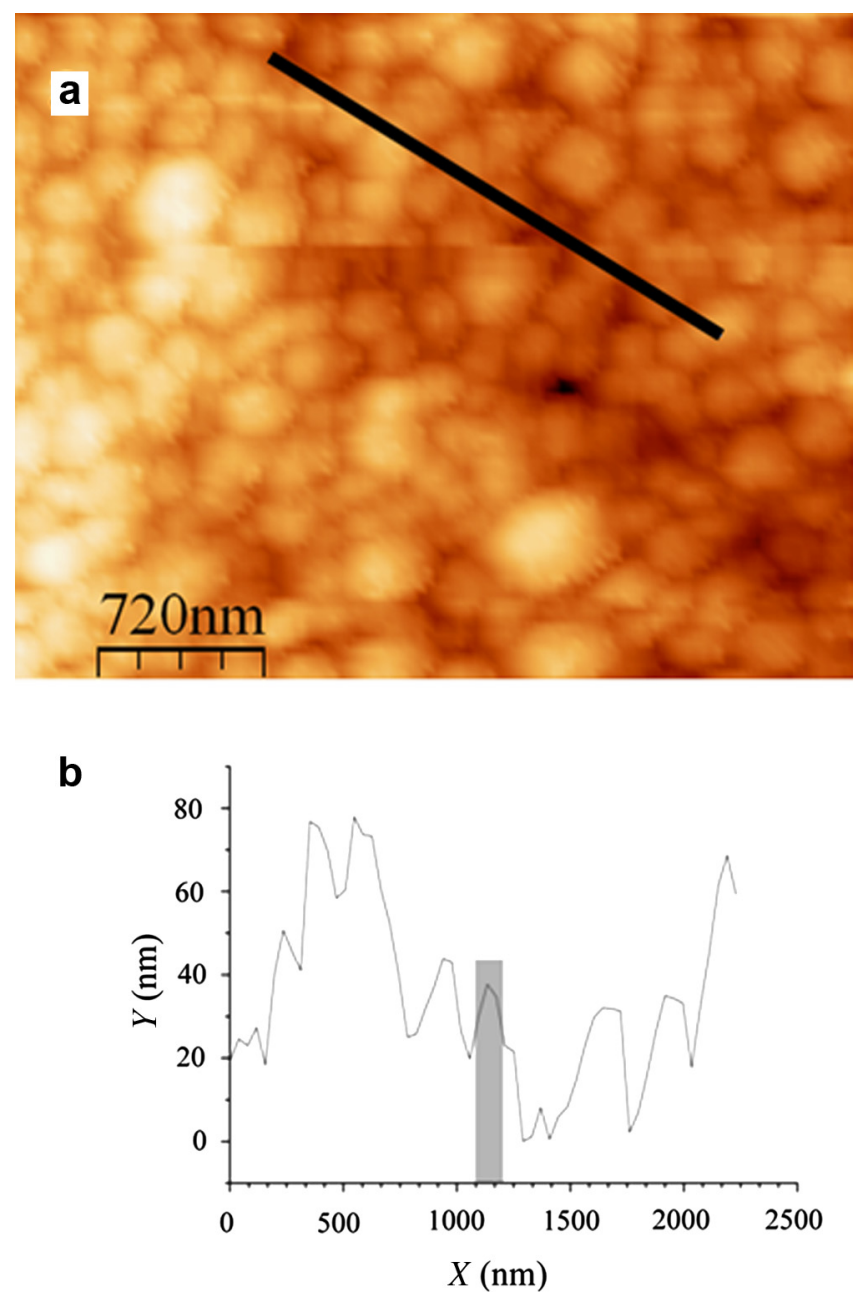

Figure 2. AFM image of solution dried casein micelles. (a) High parts of the surface are shown in bright color and low parts in dark color. A height profile (b) was generated by performing a cut of the AFM image (black line in a). The gray bar indicates a casein micelle size of $120 \mathrm{~nm}$.

concentration profile of the deposited rennin droplet at $t=t_{0}$, we used equation (3) to model the lateral concentration gradient and to determine an effective diffusion constant of rennin in the casein film. In general, the diffusion process starts with the original concentration $c=c_{0}\left(1 \mathrm{mg} \cdot \mathrm{mL}^{-1}\right)$ at $t=t_{0}$ and ends up at a concentration of $c=c_{0} / 2$ $\left(0.5 \mathrm{mg} \cdot \mathrm{mL}^{-1}\right)$ at $t=\infty$. In the present case, the concentration profile of rennin was measured after a diffusion time of $t=1200 \mathrm{~s}$. The solid line in Figure 5 represents a fit to the data, with a diffusion constant $D_{1}=5 \mu \mathrm{m}^{2} \cdot \mathrm{s}^{-1}$, a positional coordinate $d_{0}=360 \mu \mathrm{m}$ (droplet boundary at $t=t_{0}$ ) and a diffusion time $t_{1}=1200 \mathrm{~s}$. The fitted structural transition extends over a distance of $\sim 200 \mu \mathrm{m}$. The estimated diffusion 
a

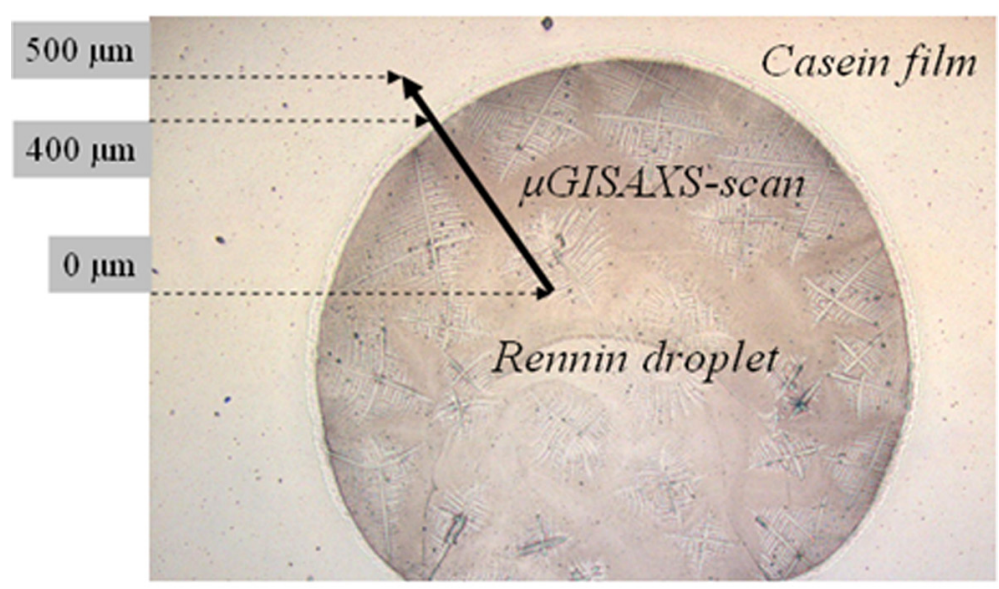

b

C
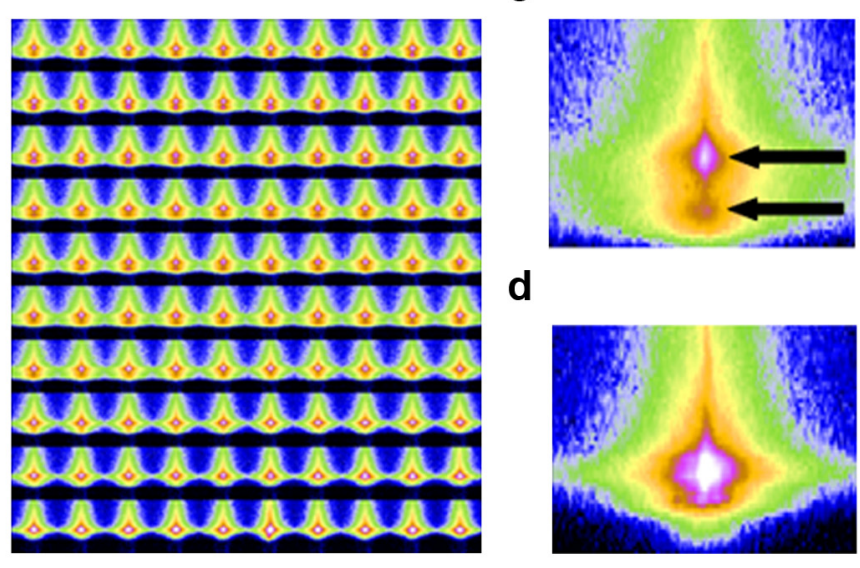

d
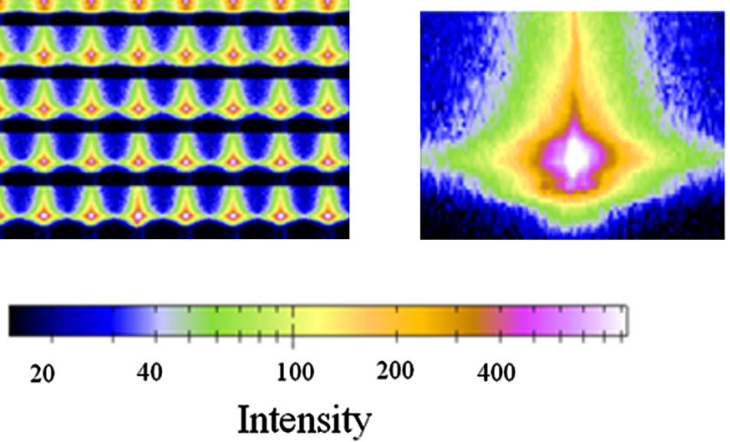

Figure 3. General view of a $\mu$ GISAXS experiment. An interesting feature is selected from an optical micrograph (a) and stepwise scanned by $\mu$ GISAXS (step-size: $5 \mu \mathrm{m}$ ). All patterns of the scan are shown (b), beginning with the first pattern measured in the rennin droplet and then line by line up to the end of the scan in the casein film. Two representative patterns (Yoneda region) measured within (c) and outside (d) the rennin droplet in the casein film are shown for better clarity. Arrows in (c) denote the Yoneda peaks at the exit angles $\alpha_{\mathrm{f}}=0.052^{\circ}$ and $0.12^{\circ}$. 


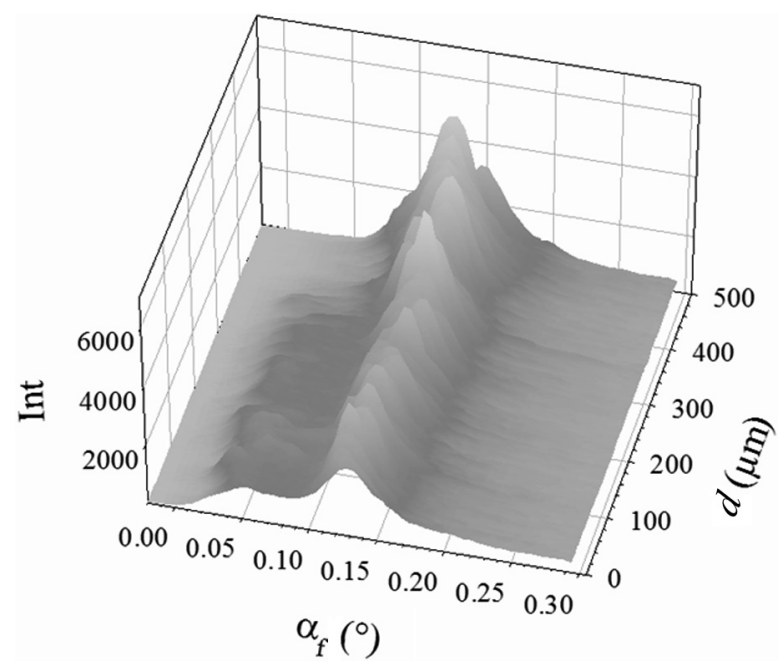

Figure 4. Evolution of the detector scan (Int versus $\alpha_{\mathrm{f}}$ ) as a function of the $\mu$ GISAXS scanning position $d$. Transition from two to one Yoneda peak takes place between $d=300$ and $400 \mu \mathrm{m}$.

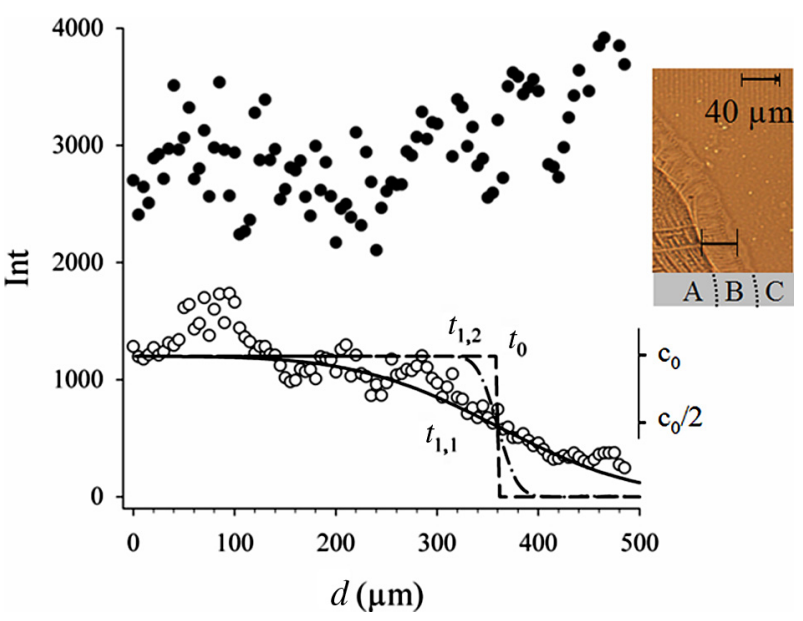

Figure 5. The plotting of the Yoneda peak maxima at $\alpha_{\mathrm{f}}=0.052^{\circ}$ (white dots) and $\alpha_{\mathrm{f}}=0.12^{\circ}$ (black dots) as a function of the $\mu$ GISAXS scanning position $d$ reveals a strong dependence between both peaks. Diffusion profiles are shown at times $t_{0}=0$ (dashed line) and $t_{1}=1200 \mathrm{~s}$ with diffusion coefficients of $D=0.1 \mu \mathrm{m}^{2} \cdot \mathrm{s}^{-1}$ (dash-dotted line) and $D=5 \mu \mathrm{m}^{2} \cdot \mathrm{s}^{-1}$ (solid line). The inserted picture shows the diffusion zone (B) between the rennin $\operatorname{droplet}(\mathrm{A})$ and the casein film $(\mathrm{C})$. The benchmark and the footprints of an overilluminated $\mu$ GISAXS scan are also shown. 
coefficient is of the same order of magnitude as found for effective diffusion coefficients of proteins in cheese $\left(1 \mu \mathrm{m}^{2} \cdot \mathrm{s}^{-1}\right)$ [29]. The effective diffusion coefficient $(D)$ of rennin is approximately one order of magnitude lower than that in free solution $\left(D_{\infty}\right)$ in accordance with the literature $[14,25]$. In order to determine the maximum error of the estimated effective diffusion constant, we simulated a concentration profile over the diffusion zone of $d=40 \mu \mathrm{m}$, since the inserted optical micrograph of another, comparable sample (shown in Fig. 5) reveals a diffusion zone of this size. The simulated curve is shown in Figure 5 as a dash-dotted line. In this case, the resulting diffusion constant was $D_{1}=0.1 \mu \mathrm{m}^{2} \cdot \mathrm{s}^{-1}$. The discrepancy between the scanning distance obtained from the $\mu$ GISAXS scan and from the optical micrograph could be a result of the extended footprint of the X-ray beam perpendicular to the scanning direction. Because of this extension the $\mu$ GISAXS experiment could, especially at positions in the diffusion zone $\mathrm{B}$, also average over the adjacent zones $A$ (rennin modified casein film) or C (casein film) and additionally broaden the transition. However, we were not able to quantify this effect because the beam did not leave a footprint on the sample. For that reason, the exact scanning path across the boundary region could not be exactly reconstructed. Beam footprints resulting from radiation damage could be detected for a sampling time 10 times higher than the used measurement time per GISAXS pattern (shown in Fig. 5, inserted picture).

The mean moved distance of diffusing molecules is proportional to $(D \cdot t)^{0.5}$ because of their random walk. External forces or convective flows induced by temperature or pressure gradients could cause deviations from the square root law [24].

In contrast to the lateral rennin concentration gradient, a measurement of the vertical one is difficult since the X-ray beam completely penetrates the casein film due to its low absorbance of X-rays [19]. However, since the intensity of the X-ray beam decreases exponentially with penetration depth, most of the scattering information results from surface-near film structures.

Structural information concerning the dimension of the casein micelles was extracted from out-of-plane scans taken at the critical angle of casein. Two normalized cuts taken from representative $\mu$ GISAXS measurements inside and outside the rennin droplet are shown in Figure 6. The scattering functions exhibit three pronounced shoulders. Beginning with the shoulder at low $Q_{y}$ values, these features can be assigned to casein micelles, a smaller casein component (e.g. casein mini-micelle or casein submicelle) and CCP particles. The data were fitted with a form-factor model in order to analyze the out-of plane cuts in more detail [5]. The model fits are indicated by solid lines in Figure 6a and describe the out-ofplane data very well. Size distributions for all three components were calculated from the fitted parameters and are shown in the right-hand side of Figure 6. Two important findings result from this analysis. On the one hand, main changes occur in the width of the size distributions: it broadens under the influence of the rennin enzyme. On the other hand, there is no strong influence of the rennin enzyme on the mean sizes of the three components. Only a decrease of the mean sizes in the range of $1 \mathrm{~nm}$ was found in case of the casein micelles and the smaller casein components.

The experimental results can be explained on the basis of a rennin concentration gradient, which was formed after deposition of the rennin droplet on the surface of the spin-coated casein film. The droplet diffused into the casein film and formed a rennin concentration gradient. Thereby, casein micelles embedded in the casein film became solubilized and so a target for the rennin enzyme reaction. Consequently, the casein micelles lost their outer 

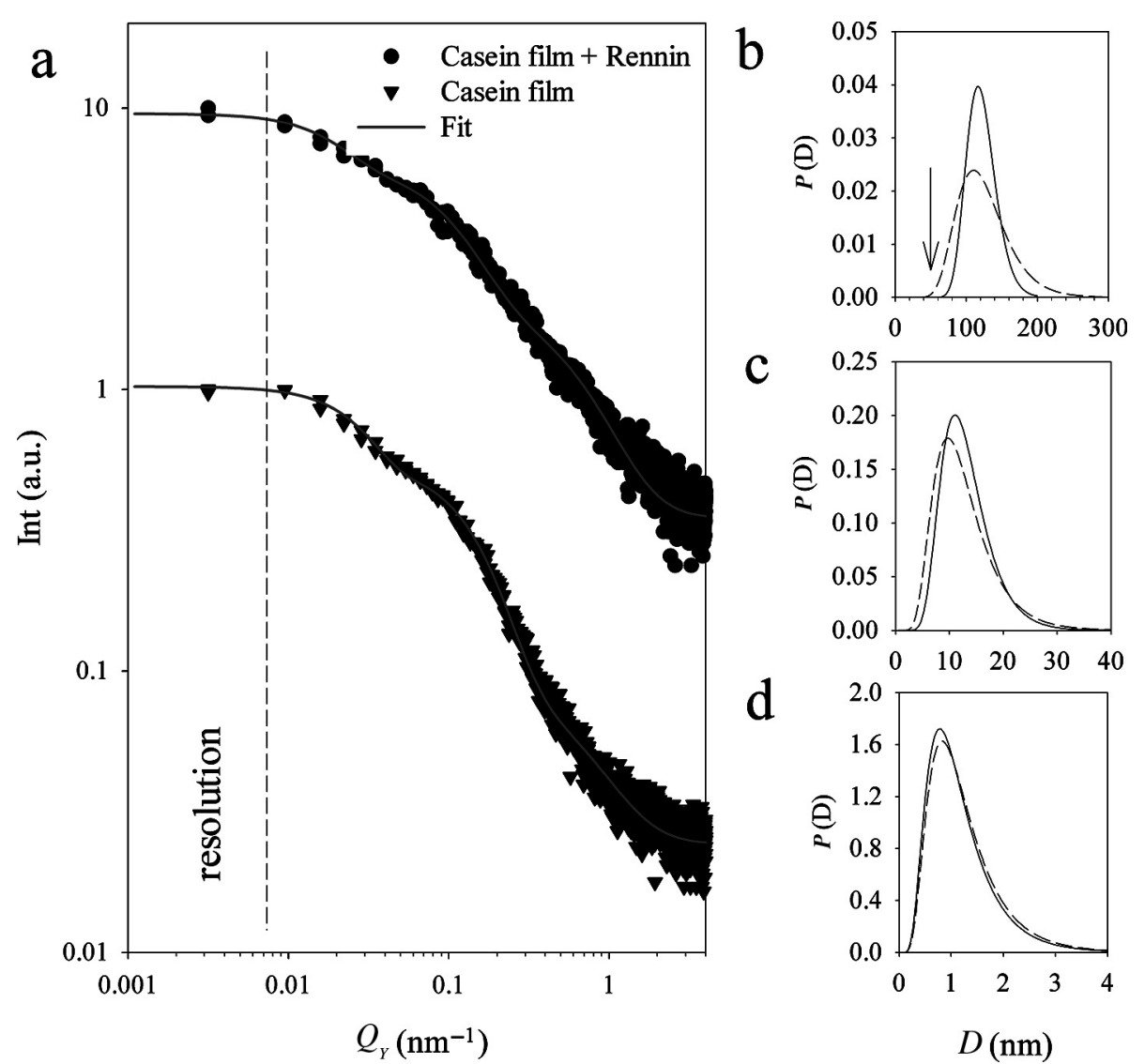

C

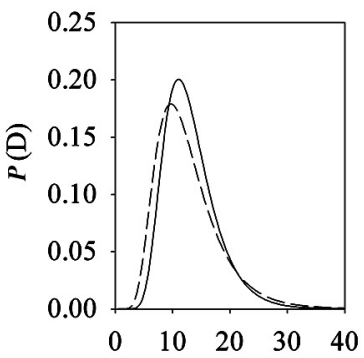

d

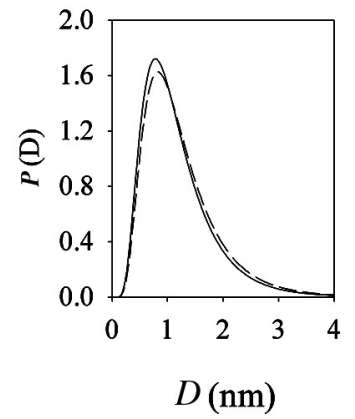

Figure 6. (a) Comparison of the scattering functions, measured within the area of the rennin droplet (dots) and outside in the casein film (triangles): fits to the scattering functions are indicated by solid lines. Calculated size distributions from fits corresponding to the casein film only (solid lines) and to the rennin droplet (dashed lines) are shown for casein micelles (mean size $120 \mathrm{~nm}$ ) in (b), for the casein micelle substructure (mean size: $12 \mathrm{~nm}$ ) in (c) and for CCP particles (mean size: $1 \mathrm{~nm}$ ) in (d).

$\kappa$-casein layer and became smaller by $20 \mathrm{~nm}$. During the evaporation of the droplet, the enzyme-treated casein micelles sedimented back on the rough surface of the remaining casein film. Those casein micelles that filled the rough cavities became visible in the scattering experiment as larger agglomerates. Others, which fell on smoother surface areas, became visible as casein micelles diminished by $20 \mathrm{~nm}$. This can be seen in particular at the left wing of the casein micelle size distribution measured within the rennin droplet (see Fig. 6b), which shifts toward smaller sizes by exactly $20 \mathrm{~nm}$.

\section{CONCLUSION}

Grazing incidence small angle X-ray scattering is an advanced method to investigate the structure of bio(polymer) films. In particular, there is potential in the actual debate of casein micelle structure since the 
method represents a link between wellestablished scattering methods and imaging techniques which are conducted on films deposited on surfaces. Especially GISAXS scanning experiments with micrometersized X-ray beams allow to handle difficulties due to the high polydispersity of casein samples.

We applied scanning $\mu$ GISAXS experiments to investigate the influence of rennin enzyme deposited as a droplet on a spincoated casein film. As a striking feature of the $\mu$ GISAXS pattern, a duplicated Yoneda peak was observed for the measurements performed inside the droplet. This was attributed to an island formation on the film surface due to rennin action. No effect on the mean sizes of the casein micelle components but a broadening of their size distribution was discovered. The experimental results were explained by the fact that only the surface near casein micelles became solved and degraded by the rennin enzyme. The rest of the casein micelles in the film kept their native dimension since they allowed no contact surface for the enzyme reaction.

The described $\mu$ GISAXS scanning method is suited for structural investigations on subsequently modified casein film surfaces. The scans allow the analysis of concentration profiles of enzymes in casein films. The estimated effective diffusion coefficient of rennin was in the same order of magnitude as found for proteins in cheese. However, the estimated value still has a large systematic error because of the extended footprint of the X-ray beam on the sample. Future GISAXS experiments with beam sizes $\leq 100 \mathrm{~nm}$ will allow even more precise scans of structural gradients.

Moreover, GISAXS experiment using X-ray micro-/nanobeams on a simultaneously imaged casein film could provide new insights into the internal structure of casein micelles. The resolution of the currently available optical microscopy technique is too low to image single casein micelles and substructures of these micelles.
Future sub- $\mu$ GISAXS-AFM in-situ experiments could make a breakthrough since casein micelles with different surface topologies could be selected and investigated more closely in view of a substructure. In view of implications in dairy science, the described method may be useful to understand processes in which structured surfaces are built or modified.

Acknowledgements: Casein sample was provided by Alexander Tolkach (TU MunichWeihenstephan). We thank Harald Müller and Lionel Lardiere (ESRF) for technical assistance. The authors acknowledge financial support from the FP6 SAXIER grant.

\section{REFERENCES}

[1] Cameron R.E., Jalil M.A., Donald A.M., Diffusion of bovine serum albumin in amylopectin gels measured using Fourier transform infrared microspectroscopy, Macromolecules 27 (1994) 27082713.

[2] Cantor C.R., Schimmel P.R., Biophysical Chemistry. Part II: Techniques for the Study of Biological Structure and Function, W. H. Freeman and Co., New York, USA, 1980.

[3] Dalgleish D.G., Spagnuolo P.A., Goff H.D., A possible structure of the casein micelle based on high-resolution field-emission scanning electron microscopy, Int. Dairy J. 14 (2004) 1025-1031.

[4] Fox P.F., Brodkorb A., The casein micelle: historical aspects, current concepts and significance, Int. Dairy J. 18 (2008) 677-684.

[5] Gebhardt R., Burghammer M., Riekel C., Roth S.V., Müller-Buschbaum P., Structural changes of casein micelles in a calcium gradient film, Macromol. Biosci. 8 (2008) 347-354.

[6] Gebhardt R., Doster W., Friedrich J., Kulozik U., Size distribution of pressuredecomposed casein micelles studied by dynamic light scattering and AFM, Eur. Biophys. J. 35 (2006) 503-509.

[7] Gebhardt R., Vendrely C., Burghammer M., Riekel C., Characterization of the boundary 
zone of a cast protein drop: fibroin betasheet and nanofibril formation, Langmuir 25 (2009) 6307-6311.

[8] Hammersley A., Available at: http://www. esrf.fr/computing/scientific/FIT2D/.

[9] Hansen S., Bauer R., Lomholt S.B., Quist K.B., Pedersen J.S., Mortensen K., Structure of casein micelles studied by small-angle neutron scattering, Eur. Biophys. J. 24 (1996) 143-147.

[10] Henke B.L., Available at: http://henke.lbl. gov/optical_constants/.

[11] Holt C., de Kruif C.G., Tuinier R., Timmins P.A., Substructure of bovine casein micelles by small-angle X-ray and neutron scattering, Colloids Surf. A: Physicochem. Eng. Asp. 213 (2003) 275-284.

[12] Horne D.S., Casein interactions: casting light on the black boxes, the structure in dairy products, Int. Dairy J. 8 (1998) 171-177.

[13] Horne D.S., Casein micelle structure: models and muddles, Curr. Opin. Colloid Interface Sci. 11 (2006) 148-153.

[14] Johnson E.M., Berk D.A., Jain R.K., Deen W.M., Hindered diffusion in agarose gels: Test of effective medium model, Biophys. J. 70 (1996) 1017-1023.

[15] Kulozik U., Tolkach A., Bulca S., Hinrichs J., The role of processing and matrix design in development and control of microstructures in dairy food production - a survey, Int. Dairy J. 13 (2003) 621-630.

[16] Marchin S., Putaux J., Pignon F., Léonil J., Effects of the environmental factors on the casein micelle structure studied by cryo transmission electron microscopy and small-angle X-ray scattering/ultrasmall-angle X-ray scattering, J. Chem. Phys. 126 (2007) 045101.

[17] Müller-Buschbaum P., Gebhardt R., Maurer E., Bauer E., Gehrke R., Doster W., Thin casein films as prepared by spin-coating: influence of film thickness and of $\mathrm{pH}$, Biomacromolecules 7 (2006) 1773-1780.

[18] Müller-Buschbaum P., Gebhardt R., Roth S.V., Metwalli E., Doster W., Effect of calcium concentration on the structure of casein micelles in thin films, Biophys. J. 93 (2007) 960-968.

[19] Parratt L.G., Surface studies of solids by total reflection of X-rays, Phys. Rev. 95 (1954) 359-369.

[20] Pechkova E., Roth S.V., Bürghammer M., Fontani D., Riekel C., Nicolini C., Micro-
GISAXS and protein nanotemplate crystallization: methods and instrumentation, J. Synchrotron Radiat. 12 (2005) 713-716.

[21] Pignon F., Belina G., Narayanan T., Paubel X., Magnin A., Gésan-Guiziou G., Structure and rheological behavior of casein micelle suspensions during ultrafiltration process, J. Chem. Phys. 121 (2004) 8138-8146.

[22] Regnault S., Thiebaud M., Dumay E., Cheftel J.C., Pressurisation of raw skim milk and of a dispersion of phosphocaseinate at $9{ }^{\circ} \mathrm{C}$ or $20^{\circ} \mathrm{C}$ : effects on casein micelle size distribution, Int. Dairy J. 14 (2004) 55-68.

[23] Riekel C., Burghammer M., Davies R., Gebhardt R., Popov D., Fundamentals of non-crystalline diffraction with microfocus techniques, in: García-Gutiérrez M., Nogales A., Gómez M., Ezquerra T.A., Applications of Synchrotron Light to Non-Crystalline Diffraction in Materials and Life Sciences, Springer, Heidelberg, Germany, 2008, pp. 91-104.

[24] Roth S.V., Autenrieth T., Grubel G., Riekel C., Burghammer M., Hengstler R., Schulz L., Müller-Buschbaum P., In situ observation of nanoparticle ordering at the air-watersubstrate boundary in colloidal solutions using X-ray nanobeams, Appl. Phys. Lett. 91 (2007) 091915-1-3.

[25] Saltzman W.M., Langer R., Transport rates of proteins in porous materials with known microgeometry, Biophys. J. 55 (1989) 163171.

[26] Schoeck J., Davies R.J., Martel A., Riekel C., Na-cellulose formation in a single cotton fiber studied by synchrotron radiation microdiffraction, Biomacromolecules 8 (2007) 602-610.

[27] Shukla A., Narayanan T., Zanchi D., Structure of casein micelles and their complexation with tannins, Soft Matter 5 (2009) 2884-2888.

[28] Walstra P., Casein sub-micelles: do they exist?, Int. Dairy J. 9 (1999) 189-192.

[29] Walstra P., Wouters J.T.M., Geurts T.J., Dairy Science and Technology, 2nd edn., Taylor \& Francis Group, Boca Raton, 2006.

[30] Waugh D.F., Noble R.W. Jr, Casein micelles. Formation and structure II, J. Am. Chem. Soc. 87 (1965) 2246-2257.

[31] Yoneda Y., Anomalous surface reflection of X-rays, Phys. Rev. 131 (1963) 2010-2013. 